\title{
The Design of International Trade Practice Analog Teaching System YANG Wenwen ${ }^{1, a}$ \\ ${ }^{1}$ Jiangxi college of foreign study, Nanchang 330099, China \\ ayangwenwen@126.com
}

Keywords: International Trade Practice; Analog Teaching; JSP technology

\begin{abstract}
With the advent of the knowledge economy, companies increasingly strong demand for talent, especially with import and export trade practice the theoretical knowledge but also has hands-on skills medium professionals' increasingly strong demand. However, China's vocational education and management by the traditional mode of education and educational deeper thought to the concept of competency-based education has not yet fully formed in the teaching field, especially for this type of content as the international trade complex, knowledge practicality are highly professional. In the traditional teaching model, students learn inefficient, which is caused by the current demand for talent gap related to expanding the main reason for the urgent need to change this situation we have to reform the traditional teaching methods and teaching materials in the existing model based on Based JSP technology to develop new assisted instruction software to meet the learning needs of the majority of students, accelerate the training speed of International Trade Practice talents.
\end{abstract}

\section{Introduction}

Along with the opportunity to join the WTO trade rights and decentralization, China will have more and more enterprises into the international business competition brought about by globalization, and that this makes familiar with international trade theory and practice, master of international trade regulations, skilled foreign language, proficient e-commerce for international trade community with practical skills needed to become popular talent. Professional teaching international business class should meet the current needs of the community, a reasonable set curriculum, changing teaching concepts, clear teaching objectives, improve teaching content, improve teaching methods, practical training in international trade professionals. With the continuous development and use of computer technology and network technology, we have more and better choices in teaching [1-3]. The establishment of international trade practice simulation laboratory, the use of international trade teaching software, through the computer network to a virtual environment of international trade, conducted simulation teaching, allowing students to handle import and export business in almost real-world environment, which will learn the theory of and practice combine true, this may be the best choice for us in this course teaching.

Scenario simulation teaching methods, classroom and community separator for solving, learning and out of touch with problems of theory and practice separation has positive significance cannot be underestimated. International Trade Practice simulated teaching is highly bound to establish a teaching method based on the theory and practice of international trade, it was adapted to the application of International Trade professional training compound talents that goal. In a classroom-based teaching model of international trade practice, focusing on the theoretical knowledge of the teaching profession, teachers often stay in the presentation to explain concepts and methods, students just passively absorb mechanically understand these universal laws , independence and idealized body of knowledge, but in practical work, will have to face a variety of complex specific circumstances, it needs to use a variety of relevant knowledge creatively to solve these realities that exist in business problems.

Simulation teaching provides students with a practical simulation platform for students to consciously experience the theoretical knowledge and practical to combine, and then low-cost, high efficiency integrated students of all abilities. At the same time, it is also out of the current 
international trade practice teaching cannot effectively implement the best way to resolve this dilemma.

\section{Theory and technical analysis}

Analog pedagogy. Simulation teaching is a kind of teaching methods and teaching environment for goal-directed behavior to guide teaching model, so that the participants play a role in realistic situations and people and things, and which interact to achieve the expected learning purposes [4]. Analog Devices Analog teaching into teaching and simulation situational teaching two categories. Analog Devices Analog Devices rely mainly on teaching as a teaching support, which is characterized by its own student feedback sentiment correct and timely corrections essentials simulation training. Analog situational teaching is mainly based professional learning requirements, simulate a social scene, through the design of specific scenes, characters, events, allow students to enter the relevant role, similar to real-life scenarios for reference, to imitate, compare, optimization, and repeated the exercise, in order to achieve and enhance the ability of the theory of sublimation. Simulation scenarios teaching pedagogy combines the advantages of the practice of teaching, case teaching, teaching mode is a way to improve the quality of education level of modern teaching. Simulation teaching combined with professional background and industry characteristics, allow students to simulate the role of professional positions in teacher-led, student-centered practice simulation, resulting in teacher-student interaction. Simulation teaching generally in accordance with the creation of scenarios - organization and preparation - practical exercises - a few steps to expand the summary evaluation, it broke the centrality of teachers to achieve the organic combination of theoretical knowledge and professional practice conducive Applied Talents .

Considering the wide range of development technologies, we selected the architecture B / S (browser / server) mode, the simulation teaching system architecture B / S model shown in Figure 1.

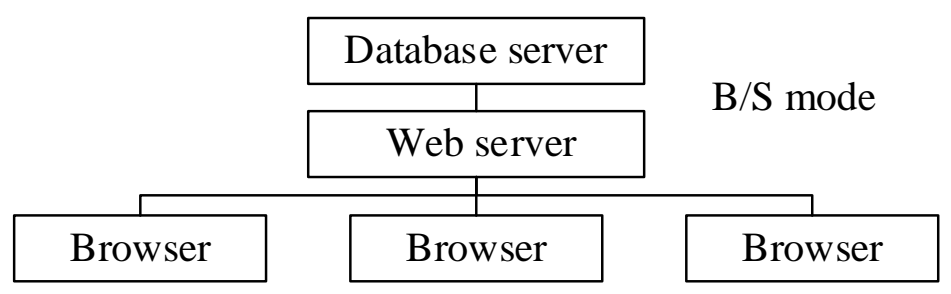

Figure 1. System structure of B/S

JSP technology. JSP is Java server pages for short. Mosaic is pure Java code to implement a dynamic function of technology in HTM bar. JSP technology allows Web developers and Web designers to rapidly develop and easy to maintain a dynamic Web page. Development with JSP Web application is cross-platform and can run on Windows, Linux and UNL another operating system. After Sun officially released JSP, this new Web application development technology soon attracted attention. JSP to create highly dynamic Web application provides a unique development environment. JSP Java language based on strong, has good scalability, tightly integrated with the Java Enterprise API together in a network database application development has a unique advantage.

\section{System Requirements Analysis}

International Trade Practice simulated teaching system design and requirements analysis biggest difference is that the logic of the segmentation. From the user point of view, in accordance with the process of learning to master the most customary way, each process will encounter what roles, role in the actual business of his own plays need to reach a clear understanding of what processes can. But for system design, by contrast, is mainly due to the system data, documents, basically across multiple processes, if at the time of system implementation process to arrange the documents in accordance with the change, it will involve large data modification the amount. Relative to the reality of the international trading system, in order to make business processes more clearly the 
function of this program were largely cut details [5-6]. To arrange in the design of each role, depending on the data in the database using the document as a classification feature, by the state and the current owner of the documents required before the order to determine the rules of document flow. Functional module structure of the international trade practice teaching simulation system shown in Figure 2.

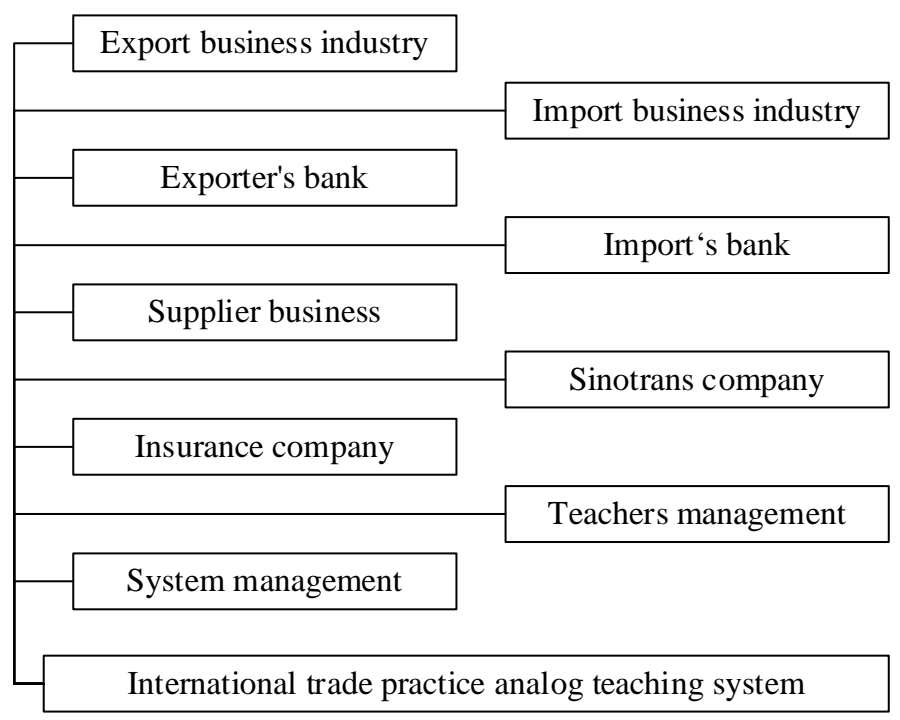

Figure 2. System module structure

International trade simulation teaching system is based on international trade practice business simulation design and development is based on the achievement of international trade practice electronic, automated system, but also a quick grasp of international business and trade documents learning system. Analog full set of documents related to international trade practice from the time the order of business to generate, transmit, receive, review, feedback of the whole process. Its main target is to simulate the international trade practice relevant enterprises, businesses various functional departments and agencies, documents and document delivery. Among them, the business simulation is carried out according to all enterprises, institutions and the actual situation of the relevant rules, the simulation of the actual business. International trade documents electronically simulated using paper-based documents to achieve, it is actually used in a variety of paper-based documents of international trade practice reproduction. Reality simulation transfer documents passed through the pages of traditional fax, mail, direct submission of various documents, such as passing.

\section{Design for International Trade Practice Analog Teaching System}

International trade simulation teaching is to make students in simulated business environment, a comprehensive, systematic, standardized grasp of international trade procedures, links and practices, operating skills and export transactions, specification writing a contract signed with the performance, information on the credit review, modify and make a single business skills for students to engage in international trade in the future and lay a good foundation for the actual operation. Courses start on the formation of analog foreign trade companies, regarding the use of the analog part of what they learn from the inquiry, the offer, but also the disk to accept, make trade contracts starting from FOB import contracts under the credit, export contracts under CIF various aspects of the students' ability to exercise actual import and export business. Goal of the entire system is based on the establishment of teaching JSP test system of international trade, and can each point in international trade practice teaching process needed to be better reflected, shown in Figure 3. 


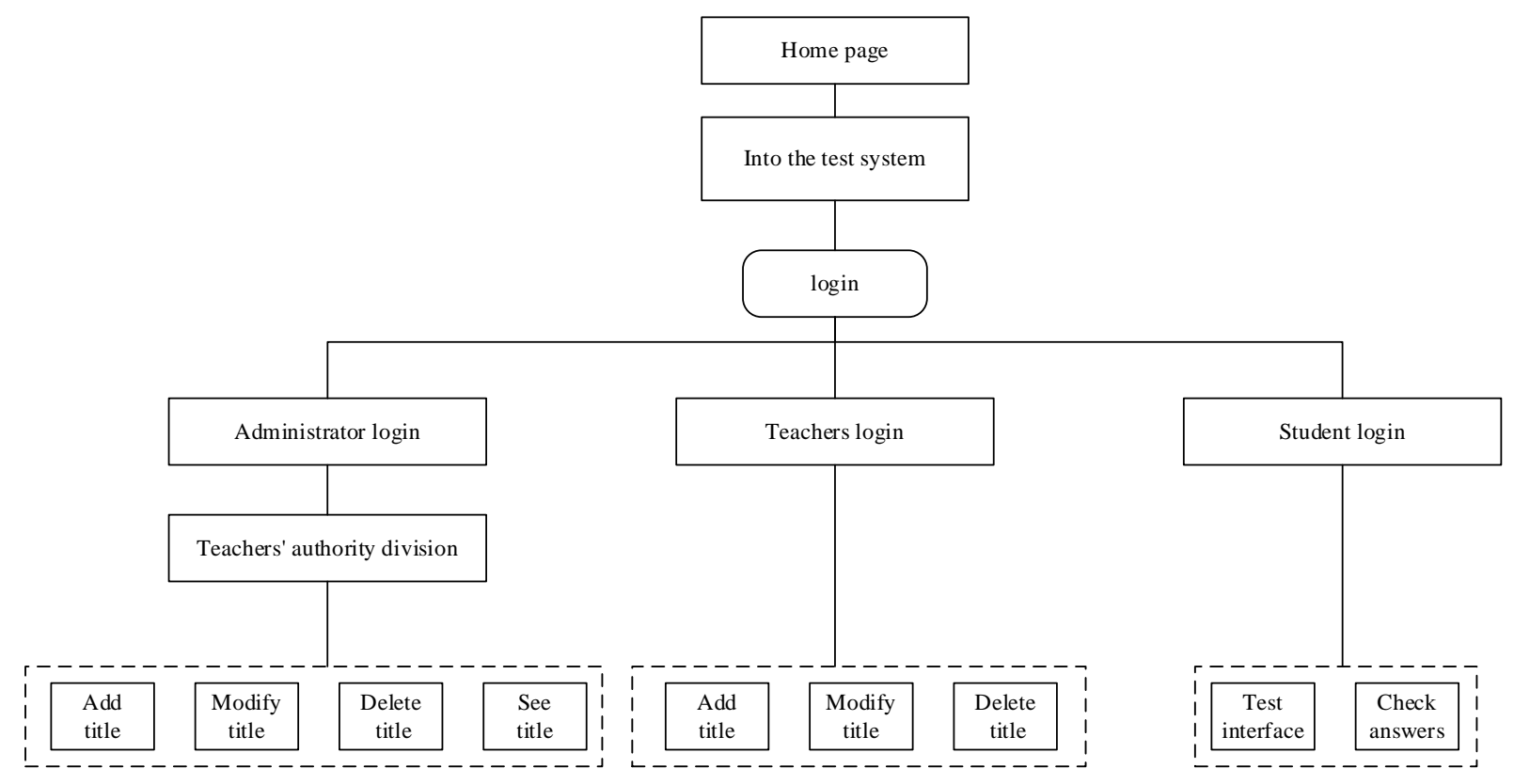

Figure 3. The structure of international trade practice analog teaching system

System fully reflects the entire import and export trade processes and procedures, and according to the different requirements of different schools of its own procedures and content modification. So that the system can meet the teaching requirements of different schools. Interactive simulation exercises, so that students can quickly adapt to the requirements of practical work in the future. Students in the course of practice, the actual process of foreign trade in the gradual deepening of the operation steps. The main practice students to master foreign trade letters, writing and production work documents. And to provide a standard reference for students to answer their own checks. Flexible setup and configuration management background, can achieve more teachers, more class distinctions management. Improved teacher ratings and marking function, teachers can work for students scored every step. And the system can calculate the student's own overall average.

\section{Conclusion}

With the continuous development and use of computer technology and network technology, we have more and better choices in teaching. This paper proposes the establishment of international trade practice simulation laboratory, through a computer network to a virtual environment of international trade, carry out simulation teaching JSP-based technology, which will be related to the theory and practice what they have learned in the real combine. In this paper, the real background of international trade simulation exercises, teaching content unity through them, so that students of international trade practice courses have a complete understanding of unity, will reflect the ability of vocational education in order to cultivate the main application, the full application of modern science and technology were subject teaching. I believe that such an analog system will also be great to meet the needs of students and teachers, the real solution to the course in the theory and practice of teaching divorced from issues so as to achieve the purpose to apply their knowledge, practical training for the community of international trade professionals.

\section{References}

[1] Ma T, Chen W. The application of simulated experimental teaching in international trade course[J]. International Education Studies, 2009, 2(1): p89.

[2] Lian Y. Region 10: Designing circuits curriculum and following good practices[J]. Circuits and Systems Magazine, IEEE, 2009, 9(1): 39-41. 
[3] Xue Y, Mei W. Application of CDIO in Improving the Teaching Model of Digital Electronic Technology $[\mathrm{J}][\mathrm{J}]$. Journal of Nanjing Institute of Technology (Social Science Edition), 2010, 1: 017.

[4] Dai Bo J W, Jiandong L, Lixin Z, et al. Constructing Professional Talent Training Model by Engineering Ability Quality Training as Main [J]. Research in Higher Education of Engineering, 2011, 6: 136-140.

[5] Ghazali A, Hamid F A. Teaching introductory level VLSI Design course to UNITEN undergraduate students[C]//Engineering Education (ICEED), 2009 International Conference on. IEEE, 2009: 40-44.

[6] Xuehua L, Yanwen W, Cuiyue W. Establishment and Implementation of Script-mode Internship of International Economics and Trade[J]. Journal of Hebei Normal University of Science \& Technology (Social Sciences), 2010, 1: 015. 